\title{
Perbandingan Angka Keberhasilan Intubasi dan Waktu Intubasi antara Menggunakan Bougie dan Purwarupa Camera-Bougie pada Maneken Simulasi Kesulitan Intubasi
}

\author{
Gavrila Diva Amelis, ${ }^{1}$ Dhany Budipratama, ${ }^{2}$ Ezra Oktaliansah ${ }^{2}$ \\ ${ }^{1}$ Rumah Sakit Umum Daerah Melawi Kalimantan Barat, \\ ${ }^{2}$ Departemen Anestesiologi dan Terapi Intensif \\ Fakultas Kedokteran Universitas Padjadjaran/RSUP Dr. Hasan Sadikin Bandung
}

\begin{abstract}
Abstrak
Penatalaksanaan jalan napas merupakan hal fundamental bagi ahli anestesi. Fiberoptik masih menjadi standar baku kesulitan intubasi, namun penggunaannya masih terbatas karena harganya mahal dan penggunaannya sulit. Purwarupa camera-bougie merupakan modalitas baru yang diharapkan dapat mengatasi keterbatasan tersebut dan menjembatani antara bougie yang sederhana dan fiberoptik yang sangat canggih. Tujuan penelitian adalah membandingkan angka keberhasilan intubasi dan waktu intubasi antara bougie dan purwarupa camera-bougie pada maneken simulasi kesulitan intubasi di RSUP Dr. Hasan Sadikin Bandung. Penelitian analitik eksperimental ini dilakukan pada 41 peserta didik Program Pendidikan Dokter Spesialis (PPDS) Anestesiologi dan Terapi Intensif Fakultas Kedokteran Universitas Padjadaran/RSUP Dr. Hasan Sadikin semester 5 sampai dengan 11 yang melakukan intubasi dengan bougie dan purwarupa camera-bougie secara bergantian dengan metode randomisasi permutasi blok pada maneken simulasi kesulitan intubasi. Penelitian dilakukan dari tanggal 16-24 Oktober 2018. Keberhasilan dan waktu intubasi dicatat dan dianalisis secara statistik dengan Uji Mc. Nemar dan Wilcoxon. Keberhasilan intubasi dengan bougie sebesar 39\% dan purwarupa camera-bougie $100 \%(\mathrm{p}<0,001)$. Waktu intubasi dengan bougie dan purwarupa camera-bougie sebesar 18,81 $(12,19)$ detik dan 7,0 $(1,47)$ detik $(\mathrm{p}<0,001)$. Simpulan, purwarupa camera-bougie meningkatkan keberhasilan intubasi dan memperpendek waktu intubasi pada maneken simulasi kesulitan intubasi.
\end{abstract}

Kata kunci: Bougie, intubasi, jalan napas sulit, maneken, purwarupa camera-bougie

\section{Comparison of Success Rate and Duration of Intubation between Bougie and Bougie-Camera Prototype in Simulated Difficult Airway Manikin}

\begin{abstract}
Airway management is fundamental for anesthesiologist. Fiberoptic is still the gold standard for difficult intubation but its expensive price and complicated handling limit its use. Bougie-camera prototype is one of the new modalities that is expected to overcome these limitations and bridge the gap between simple bougie and very sophisticated fiberoptic. The aim of this study was to compare the success rate and duration of intubation between bougie and bougie-camera prototype in simulated difficult airway manikin at Dr. Hasan Sadikin General Hospital Bandung. This experimental analytic study was conducted on 41 fifth semester anesthesiology residents of the Faculty of Medicine, Universitas Padjadjaran/Dr. Hasan Sadikin General Hospital who performed intubation with bougie and bougie-camera prototype alternately on simulated difficult airway mannequin using permutation block randomization method. This study was held during the period of 16-24th of October 2018. The success rate and duration of intubation were recorded and analyzed statistically by Mc. Nemar and Wilcoxon tests. The rate of successful intubation with bougie was 39\% and $100 \%$ with bougie-camera prototype $(\mathrm{p}<0.001)$. Duration of intubation with bougie and bougie-camera prototype was 18.81 (12.19) seconds and 7.0 (1.47) seconds $(\mathrm{p}<0.001)$. The conclusion of this study is bougie-camera prototype increases the success rate of intubation and shortens the duration of intubation on simulated difficult airway on mannequin.
\end{abstract}

Keywords: Bougie, bougie-camera prototype, difficult airway, intubation, mannequin

Korespondensi: Gavrila Diva Amelis, dr., SpAn, Rumah Sakit Umum Daerah Melawi, Jl. Kelakik km. 4, Kec. Nanga Pinoh, Kab. Melawi, Kalimantan Barat, Tlpn (0568) 21033,Email gavrila.amelis@gmail.com 


\section{Pendahuluan}

Salah satu tanggung jawab fundamental ahli anestesi adalah untuk memastikan pertukaran gas yang adekuat pada pasien. Kegagalan menjaga oksigenasi selama lebih dari beberapa menit dapat mengakibatkan cedera anoksik yang berbahaya. ${ }^{1}$

Teknik penatalaksanaan jalan napas telah mengalami banyak kemajuan, namun kesulitan penatalaksanaan jalan napas sulit masih merupakan masalah perioperatif yang tidak dapat diabaikan. Kegagalan penatalaksanaan pasien dengan jalan napas sulit mengakibatkan sekitar 25-30\% kematian akibat anestesi. ${ }^{1,2}$ Kesulitan intubasi yang tidak terprediksi terjadi pada 5,8\% pasien. $^{3}$ Mayoritas penatalaksanaan jalan napas sulit disebabkan oleh visualisasi laring yang sulit saat laringoskopi direk dan hal ini sering kali sulit diprediksi sebelum induksi anestesi. ${ }^{4,5}$

Berbagai modalitas dapat digunakan untuk mengatasi intubasi sulit yang tidak terprediksi seperti pada posisi pasien, manipulasi laring eksternal, penggunaan stylet dan bougie, video laryngoscope, supraglottic airway device, lightwand, dan krikotiroidotomi. ${ }^{2,6}$

Beberapa penelitian telah membandingkan penggunaan modalitas tersebut dengan kelebihan dan juga kekurangan masingmasing. Bougie secara luas dipergunakan untuk memfasilitasi intubasi trakea pada laringoskopi direk dengan visualisasi grade 2 atau 3a. Penelitian sebelumnya dinyatakan bahwa bougie dapat meningkatkan angka keberhasilan pada pasien dengan kesulitan intubasi. ${ }^{7,8}$ Penggunaan video laryngoscope dan fiberoptic telah meningkatkan angka keberhasilan intubasi pada pasien dengan jalan napas sulit, namun penggunaannya terbatas karena mahal, ketersediaan terbatas, dan keterampilan ahli anestesi yang kurang.,5,9

Pada saat ini masih terdapat kesenjangan bougie yang sangat sederhana dengan video laryngoscope dan fiberoptic yang canggih dalam penatalaksanaan kesulitan intubasi. ${ }^{10}$

Purwarupa camera-bougie merupakan salah satu modalitas yang diharapkan dapat dipergunakan untuk mengatasi kekurangan pada modalitas tersebut. Purwarupa camerabougie menyediakan visualisasi laring dengan sumber cahaya dan juga fleksibilitas seperti bougie untuk memfasilitasi intubasi terutama pada pasien yang tidak terprediksi memiliki jalan napas sulit. Belum ada literatur yang membahas mengenai purwarupa camerabougie ini. Prinsip purwarupa camera-bougie ini mirip dengan penggabungan antara video laryngoscope dan bougie. Purwarupa camerabougie ini terbuat dari alat dan bahan yang tidak membuat trauma pada jalan napas, namun profil keamanan alat belum diketahui. Tujuan dilakukannya penelitian ini adalah membandingkan angka keberhasilan intubasi dan juga waktu intubasi antara bougie dan purwarupa camera-bougie pada maneken simulasi kesulitan intubasi.

\section{Subjek dan Metode}

Penelitian ini merupakan penelitian analitik eksperimental dengan studi silang yang dilaksanakan pada peserta didik Program Pendidikan Dokter Spesialis atau PPDS Anestesiologi dan Terapi Intensif Fakultas Kedokteran Universitas Padjadjaran (FKUP)/ RSUP dr. Hasan Sadikin Bandung (RSHS) yang memenuhi kriteria inklusi dan tidak termasuk eksklusi. Kriteria inklusi, yaitu peserta didik PPDS Anestesiologi semester 5 s.d. 11 (Level Kompetensi 2 dan 3). Kriteria eksklusi, yaitu peserta didik sedang menjalani stase di luar RSHS saat penelitian dilakukan. Jumlah sampel ditentukan berdasar atas rumus untuk menguji perbedaan 2 proporsi data berpasangan dan didapatkan jumlah sampel minimal adalah 34 orang.

Penelitian ini dilakukan setelah mendapat persetujuan dari Komite Etik Penelitian Kesehatan FKUP/RSHS Bandung. Sebelum penelitian, peneliti menjelaskan tata cara intubasi menggunakan bougie dan purwarupa camera-bougie pada maneken simulasi kesulitan intubasi (Gambar 1 dan 2) dan diberi kesempatan mengenal alat. Purwarupa camera-bougie ini merupakan suatu endoskop dengan panjang $150 \mathrm{~cm}$ dan diameter $5 \mathrm{~mm}$ dengan sebuah kawat penyangga sepanjang 


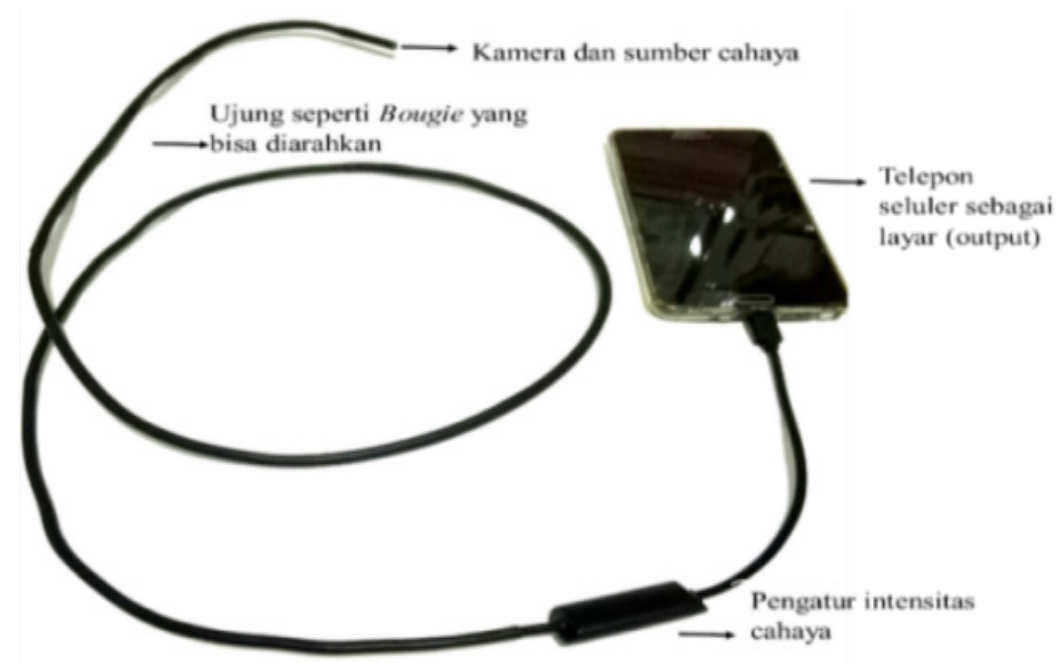

\section{Gambar 1 Purwarupa Camera-bougie}

Sumber: dokumentasi pribadi

$28 \mathrm{~cm}$ dari ujung distalnya untuk membentuk dan mengarahkannya ke depan laring serta memiliki panjang $3,5 \mathrm{~cm}$ dan diameter 5,5 mm pada ujung kameranya. Purwarupa camera-bougie ini dapat dibentuk ujungnya secara manual hingga maksimal 90 derajat untuk memudahkan menyusuri bagian bawah epiglotis. Purwarupa camera-bougie dapat difungsikan setelah kamera terhubung dengan telepon seluler yang telah terpasang aplikasi khusus, yaitu CameraFi untuk menjalankan kamera tersebut. Setiap subjek penelitian diberikan maksimal tiga kali kesempatan untuk melakukan intubasi mempergunakan kedua alat tersebut. Subjek penelitian melakukan intubasi dengan kedua alat secara bergantian dengan randomisasi permutasi blok.

Tata cara intubasi menggunakan bougie, yaitu subjek penelitian membuka mulut maneken dengan cara teknik cross-finger,

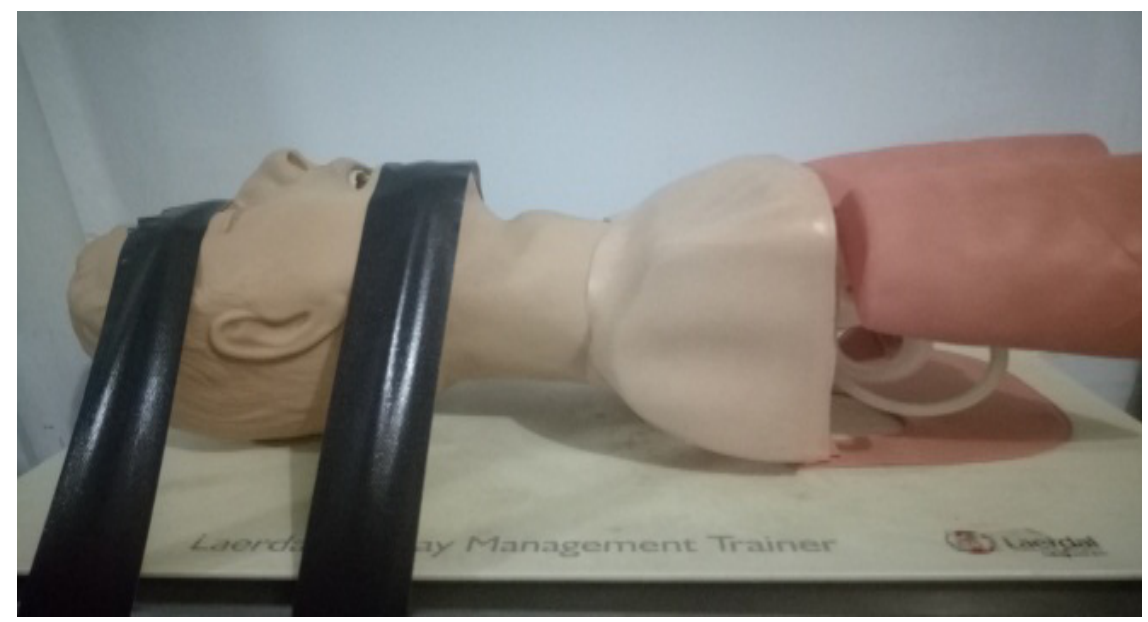

Gambar 2 Maneken Simulasi Kesulitan Intubasi. Cormack-Lehane Grade 3*

Keterangan: *)Fiksasi kepala pada posisi netral dan buka mulut dikurangi 30\%. Menggunakan bilah Macintosh nomor 3, dipastikan hanya ujung epiglotis yang terlihat.

Sumber: dokumentasi pribadi 
Tabel 1 Perbandingan Keberhasilan Intubasi antara Menggunakan Bougie dan Purwarupa Camera-bougie

\begin{tabular}{lcc}
\hline \multicolumn{1}{c}{ Metode Intubasi } & $\begin{array}{c}\text { Berhasil } \\
\text { n (\%) }\end{array}$ & $\begin{array}{c}\text { Tidak Berhasil } \\
\text { n (\%) }\end{array}$ \\
\hline Bougie & $16(39)$ & $25(61)$ \\
Purwarupa Camera-Bougie & $41(100)$ & $0(0)$ \\
\hline
\end{tabular}

Keterangan: nilai p (Uji Mc. Nemar) $<0,001$

kemudian dilaksanakan larongoskopi direk. Bougie dengan bentuk kurva yang sudah distandarkan untuk semua subjek dimasukkan menyusuri bagian bawah epiglotis ke arah trakea sampai diperkirakan ujung bougie sudah berada di trakea, kemudian endotracheal tube diinsersikan menyusuri bougie tersebut. Balon endotracheal tube dikembangkan, lalu endotracheal tube disambungkan dengan bagvalve mask dan dilakukan inflasi untuk melihat pengembangan kedua paru. Apabila intubasi pada maneken gagal masuk ke paru atau gagal dilakukan dalam waktu $\leq 150$ detik pada percobaan yang pertama, subjek penelitian diberikan kesempatan melakukan intubasi pada percobaan kedua dan ketiga.

Pada intubasi menggunakan purwarupa camera-bougie subjek penelitian membuka mulut maneken dengan teknik cross-finger, kemudian dilakukan laringoskopi direk. Purwarupa camera-bougie itu yang sudah dibentuk menyerupai kurva lalu dimasukkan ke dalam mulut. Sesudah itu, pandangan subjek penelitian tertuju pada layar telepon seluler sambil mengarahkan purwarupa camera-bougie menyusuri bagian bawah epiglotis. Setelah laring terlihat dengan jelas purwarupa camera-bougie dimasukkan ke dalam trakea dan endotracheal tube dapat segera diinsersikan menyusuri purwarupa camera-bougie tersebut. Balon endotracheal tube dikembangkan, kemudian disambungkan dengan bag-valve mask dan dilakukan inflasi paru. Sama halnya dengan upaya percobaan pada bougie, subjek penelitian diberikan kesempatan maksimal tiga kali intubasi. Waktu intubasi dan keberhasilan intubasi dicatat pada lembar penelitian dan dilakukan uji statistik menggunakan Uji Mc. Nemar, Wilcoxon, dan Exact Fisher. Kemaknaan hasil uji ditentukan berdasar atas nilai $\mathrm{p}<0,05$. Data yang diperoleh dicatat dalam formulir khusus kemudian diolah melalui program SPSS versi 24.0 for windows.

\section{Hasil}

Penelitian dilakukan terhadap 41 orang peserta didik PPDS Anestesiologi dan Terapi Intensif Fakultas Kedokteran Universitas Padjadjaran (FKUP)/RSUP dr. Hasan Sadikin Bandung (RSHS). Angka keberhasilan intubasi pada maneken simulasi kesulitan intubasi dengan menggunakan bougie adalah 39\%, sedangkan angka keberhasilan purwarupa camera-bougie adalah $100 \%$, perbedaan ini secara statistik dengan Uji Mc. Nemar sangat bermakna $(\mathrm{p}<0,001$; Tabel 1$)$.

Tabel 2 Perbandingan Usaha Percobaan dan Waktu Intubasi antara Menggunakan Bougie dan Purwarupa Camera-bougie

\begin{tabular}{|c|c|c|c|}
\hline Parameter & Bougie & Purwarupa Camera-bougie & Nilai p \\
\hline \multicolumn{4}{|l|}{ Upaya percobaan } \\
\hline $1 \mathrm{x}$ & 9 & 41 & $<0,001^{*}$ \\
\hline$>1 \mathrm{x}$ & 7 & 0 & \\
\hline \multicolumn{4}{|l|}{ Waktu (detik) } \\
\hline Mean \pm SD & $18,81(12,19)$ & $7,0(1,47)$ & $<0,001^{* *}$ \\
\hline
\end{tabular}

Keterangan: *) berdasar atas Uji Exact Fisher; ${ }^{* *}$ ) berdasar atas Uji Wilcoxon 
Upaya percobaan intubasi yang berhasil pada maneken simulasi kesulitan intubasi yang membutuhkan percobaan intubasi $>1 \mathrm{x}$ terdapat lebih banyak pada penggunaan bougie (7 peserta didik) dibanding dengan penggunaan purwarupa camera-bougie $(0$ peserta didik) dengan perbedaan bermakna $(\mathrm{p}<0,05)$. Waktu rerata yang dibutuhkan untuk melakukan intubasi jalan napas sulit pada penggunaan bougie lebih lama $(18,81 \pm 12,19$ detik) dibanding dengan purwarupa camerabougie $(7,0 \pm 1,47$ detik) dengan perbedaan bermakna ( $\mathrm{p}<0,05$; Tabel 2).

\section{Pembahasan}

Penelitian dilakukan pada 41 peserta didik PPDS Anestesiologi dan Terapi Intensif Fakultas Kedokteran Universitas Padjadjaran/ Rumah Sakit Umum Pusat Dr. Hasan Sadikin Bandung dari semester 5 s.d semester 11 . Hasil penelitian ini menunjukkan bahwa angka keberhasilan purwarupa camera-bougie lebih tinggi dibanding dengan bougie, dengan upaya percobaan intubasi yang lebih sedikit dan waktu intubasi yang lebih singkat (Tabel 1 dan 2).

Pada penelitian ini angka keberhasilan intubasi dengan menggunakan Purwarupa camera-bougie mencapai $100 \%$. Hal ini tidak dapat dibandingkan dengan penelitian lain karena belum ada penelitian sebelumnya tentang purwarupa camera-bougie. Namun, hasil penelitian ini sama dengan angka keberhasilan purwarupa camera-bougie pada penelitian sebelumnya pada tahun 2008 dan 2012 menggunakan alat yang menyerupai purwarupa camera-bougie, yaitu video laryngoscope dengan bougie atau seeing optical stylet didapatkan bahwa keberhasilan intubasi dengan video laryngoscope adalah 100\%.,11 Namun demikian, penelitian selanjutnya pada tahun 2013 dan 2016 dinyatakan angka keberhasilan intubasi dengan video laryngoscope sebesar $78,6 \%$ dan $80,4 \%{ }^{12,13}$ Hal ini mungkin disebabkan oleh perbedaan operator yang melakukan intubasi yang bukan dilakukan oleh ahli anestesi. Selain itu, subjek penelitian pada kedua penelitian adalah pasien penyakit kritis di ICU.

Penelitian tahun 2016 membandingkan keberhasilan intubasi tersebut antara video laryngoscope dan flexible fiberoptic pada pasien dengan imobilisasi servikal, didapatkan angka keberhasilan 83\% dan 78\%. Perbedaan ini disebabkan oleh perbedaan subjek penelitian, yaitu pasien dengan variasi anatomis yang berbeda dan angka keberhasilan dalam penelitian ditentukan dengan 1 kali percobaan (first attempt intubation). ${ }^{14}$

Angka keberhasilan intubasi yang tinggi mempergunakan purwarupa camera-bougie disebabkan oleh purwarupa ini memiliki kelenturan untuk dibentuk dan diarahkan seperti bougie dan memberikan visualisasi laring atau plica vocalis pada saat intubasi dilakukan. Kemampuan purwarupa camerabougie untuk memberikan gambar visual akan mengatasi kesulitan visualisasi laring saat laringoskopi direk yang merupakan penyebab utama penatalaksanaan jalan napas sulit., ${ }^{4,8}$

Pada penelitian ini terdapat perbedaan upaya percobaan intubasi antara bougie dan purwarupa camera-bougie. Upaya percobaan intubasi menggunakan bougie yang membutuhkan percobaan intubasi $>1 \mathrm{x}$ lebih banyak dibanding dengan penggunaan purwarupa camera-bougie dengan perbedaan yang bermakna secara statistik $(\mathrm{p}<0,001)$.

Penelitian ini juga membandingkan waktu intubasi yang dibutuhkan antara menggunakan bougie dan purwarupa camerabougie. Perbedaan waktu intubasi pada intubasi yang berhasil antara pemakaian bougie dan purwarupa camera-bougie secara statistik dengan Uji Wilcoxon sangat bermakna $(\mathrm{p}<0,001)$. Pada penelitian ini rerata waktu intubasi dengan bougie 18,81 (12,19) detik, sedangkan pemakaian purwarupa camerabougie sebesar $7,0(1,47)$ detik. Perbedaan ini disebabkan oleh visualisasi glotis pada purwarupa camera-bougie yang lebih mudah dan lebih baik dibanding dengan penggunaan bougie. Visualisasi pada penggunaan bougie lebih sulit karena hanya melihat dari celah mulut saat laringoskopi direk, sedangkan pada maneken dimodifikasi terdapat buka mulut yang tidak maksimal. Pada purwarupa 
camera-bougie visualisasi glotis dapat terlihat dengan jelas pada layar telepon seluler sehingga memudahkan dilakukannya intubasi sekalipun dari celah mulut yang sempit.

Waktu intubasi dengan bougie pada penelitian ini lebih lambat dibanding dengan penelitian sebelumnya pada tahun 2003, yaitu 10,5 (8-12) detik. ${ }^{15} \mathrm{Hal}$ ini dikarenakan pada penelitian ini, subjek penelitian diberi kesempatan melakukan intubasi maksimal tiga kali percobaan sehingga pada subjek yang pernah gagal melakukan intubasi waktu intubasi yang dibutuhkan menjadi lebih lama. Namun, waktu intubasi pada penelitian ini lebih cepat dibanding dengan beberapa penelitian sebelumnya. Penelitian tahun 2011 waktu intubasi dengan bougie pada maneken yang disimulasikan memiliki jalan napas sulit sebesar 20,4 $(9,1)$ detik. $^{7}$

Keadaan ini mungkin disebabkan oleh penelitian tersebut dilakukan oleh perawat dan dokter umum yang menjadi residen emergency medicine (bukan ahli anestesi), penelitian tersebut juga hanya diberikan 1 kali kesempatan tanpa percobaan sebelumnya. Penelitian lain telah membandingkan waktu intubasi dengan bougie, video laryngoscope, dan flexible fiberoptic, yaitu 29,4 $(10,9)$ detik, 16,6 (11,2) detik, dan 30,6 $(20,0)$ detik $(\mathrm{p}<0,0001){ }^{16}$ Waktu intubasi yang dibutuhkan pada penelitian ini juga lebih cepat dibanding dengan penelitian-penelitian tersebut. Hal ini mungkin disebabkan karena pada penelitian sebelumnya subjek penelitian tidak diperbolehkan mencoba terlebih dahulu sebelum penelitian dilakukan.

Penggunaan purwarupa camera-bougie pada penelitian ini meningkatkan angka keberhasilan intubasi dengan waktu intubasi yang lebih pendek bila dibanding dengan penggunaan bougie pada maneken simulasi kesulitan intubasi. Melalui penelitian ini diharapkan bahwa purwarupa camera-bougie ini dapat dijadikan salah satu modalitas penanganan jalan napas sulit yang mudah digunakan dengan harga yang lebih murah.

Penelitian ini mempunyai keterbatasan penelitian pada maneken simulasi kesulitan intubasi. Meskipun maneken simulasi kesulitan intubasi telah menyediakan derajat kesulitan visualisasi laring untuk intubasi, namun tidak menunjukkan kondisi intubasi yang sesungguhnya pada manusia. Profil keamanan alat ini belum diuji serta modifikasi alat masih manual sehingga masih mungkin berbeda untuk setiap alat yang dibuat dan dibutuhkan penyempurnaan lanjutan dari segi kelenturannya. Penelitian selanjutnya diperlukan subjek penelitian manusia untuk menilai langsung profil keamanan dan penggunaan alat purwarupa camera-bougie tersebut.

\section{Simpulan}

Purwarupa camera-bougie tersebut memiliki keberhasilan intubasi yang lebih tinggi dan waktu intubasi yang lebih pendek dibanding dengan bougie untuk jalan napas sulit.

\section{Daftar Pustaka}

1. Ramachandran SK, Jr PAK. Definition and incidence of the difficult airway. Dalam: Hagberg CA, penyunting. Benumof and Hagberg's airway management. Edisi ke3. Philadelphia: Elsevier Saunders; 2013. hlm. 201.

2. Cook TM, MacDougall-Davis SR. Complications and failure of airway management. $\mathrm{Br} \mathrm{J}$ Anaesth. 2012;109(S1):i68-85.

3. Koh W, Kim H, Kim K, Ro Y-J, Yang H-S. Encountering unexpected difficult airway: relationship with the intubation difficulty scale. Korean J Anesthesiol. 2016;69(3):244-9.

4. Evans A, Morris S, Petterson J, Hall JE. A comparison of the seeing optical stylet and the gum elastic bougie in simulated difficult tracheal intubation: a manikin study. Anaesthesia. 2006;61:478-81.

5. Komatsu R, Kamata K, Hoshi I, Sessler DI, Ozaki M. Airway scope and gum elastic bougie with macintosh laryngoscope for tracheal intubation in patients with simulated restricted neck mobility. Br J Anaesth. 2008;101(6):863-9. 
6. Frerk C, Mitchell VS, McNarry AF, Mendonca C, Bhagrath R, Patel A, dkk. Difficult airway society 2015 guidelines for management of unanticipated difficult intubation in adults. Br J Anaesth. 2015;115(6):827-48.

7. Khan RA, Khan FA, Azam M. Comparison of the stylet and the gum elastic bougie in tracheal intubation in a simulated diffiult airway. Anaesth Pain Intens Care. 2014;18(3):256-9.

8. Messa MJ, Kupas DF, Dunham DL. Comparison of bougie-assisted intubation with traditional endotracheal intubation in a simulated difficult airway. Prehosp Emerg Care. 2011;15:30-3.

9. Norris A, Heidegger T. Limitations of videolaryngoscopy. $\mathrm{Br} \mathrm{J}$ Anaesth. 2016;117(2):148-50.

10. Scott J, Hung OR. Intubating introducers, stylets, and lighted stylets (lightwands). Dalam: Hagberg CA, penyunting. Benumof and Hagberg's airway management. Edisi ke-3. Philadelphia: Elsevier Saunders; 2013. hlm. 430-42.

11. Wahba SS, Tammam TF, Saeed AM. Comparative study of awake endotracheal intubation with glidescope videolaryngoscope versus flexible fiberoptic bronchoscope in patient with traumatic cervical spine injury. Egypt J Anaesth. 2012;28:257-60.
12. Mosier JM, Whitmore SP, Bloom JW, Snyder LS, Graham LA, Carr GE, dkk. Video laryngoscopy improves intubation success and reduces esophageal intubations compared to direct laryngoscopy in the medical intensive care unit. Crit Care. 2013;17:R237-46.

13. Hypes CnD, Stolz U, Sakles JC, Joshi RR, Natt B, Malo J, dkk. Video laryngoscopy improves odds of first-attempt success at intubation in the Intensive Care Unit : a propensity-matched analysis. Ann Am Thorac Soc. 2016;13(3):382-90.

14. Yumul R, Elvir-Lazo OL, White PF, Durra $\mathrm{O}$, Ternian A, Tamman R, dkk. Comparison of the C-MAC video laryngoscope to a flexible fiberoptic scope for intubation with cervical spine immobilization. J Clin Anaesth. 2016;31:46-52.

15. Hodzovic I, Wilkes AR, Latto IP. To shape or not to shape. Simulated bougieassisted difficult intubation in a manikin. Anaesthesia. 2003;58:775-803.

16. Koyama Y, Inagawa G, Miyashita T, Kikuchi $\mathrm{T}$, Miura N, Miki T, dkk. Comparison of the airway scope, gum elastic bougie and fibreoptic bronchoscope in simulated difficult tracheal intubation: a manikin study. Anaesthesia. 2007;62:936-9. 